\title{
Dendritic Pathology of Granule Cells in Alzheimer's Disease Is Unrelated to Neuritic Plaques
}

\author{
Gillian Einstein, ${ }^{1}$ Raquel Buranosky, ${ }^{1}$ and Barbara J. Crain ${ }^{1,2}$ \\ Departments of 'Neurobiology and 'Pathology, Duke University Medical Center, Durham, North Carolina 27710
}

\begin{abstract}
Neuritic plaques are the histologic hallmark of Alzheimer's disease (AD); however, the extent to which they are injurious to neurons is unclear. In order to investigate this problem, we intracellularly filled human dentate granule cells with Lucifer yellow in a lightly fixed slice preparation and studied the relationships between their dendrites and neuritic plaques. After counterstaining for plaques and drawing the filled granule cell dendrites, we found that there were significant differences in the morphology of dendrites in control and AD cases; granule cell dendrites from Alzheimer's cases were generally shorter, branched less profusely, and had fewer spines than those from age matched controls. Surprisingly, when dendrites traveled into plaques, they still bore spines and their morphology was distinct from that of the amyloid-stained dystrophic neurites surrounding them. Furthermore, within AD cases we found no significant differences between dendrites that were located directly beneath or passing through plaques and those that were located in plaque-free regions. We conclude that granule cell dendrites are not an integral component of plaques within their dendritic fields and that neuritic plaques have no direct effect on granule cells in the dentate gyrus.

IKey words: $\beta$-amyloid, hippocampus, dendritic morphology, lightly fixed slice, dentate gyrus, dystrophic neurites, intracellular injections]
\end{abstract}

Since Alois Alzheimer's first case report in 1907 (Alzheimer, 1986), the presence of neuritic plaques in the hippocampus and the neocortex has been a major diagnostic criterion for Alzheimer's disease (AD) (Kachaturian, 1985; Mirra et al., 1991). However, plaque number correlates only poorly with the clinical severity of the disease (Wilcock and Esiri, 1982) and it is unclear precisely what effect, if any, plaques have on neurons in their vicinity. Thus, the role plaques play in the neuronal pathology associated with $\mathrm{AD}$ is unresolved.

In an effort to understand the pathogenesis of plaque formation, previous investigations have studied the effects on surrounding neurons of an important plaque constituent, $\beta$-amyloid. Studies to determine if $\beta$-amyloid is toxic have shown that intracerebral injection of $\beta$-amyloid induces the degeneration

Received Aug. 27, 1993; revised Feb. 16, 1994; accepted Mar. 2, 1994

We thank Dr. Feri Zsuppan for helping us gather the confocal images. Ms. Yan Liu contributed expert technical assistance. This work was supported by NIA Grants AG O5128 and AG O9216. R.B. was supported by the John A. Hartford Foundation.

Correspondence should be addressed to Dr. Gillian Einstein, Department of Neurobiology, Box 3209, Duke University Medical Center, Durham, NC 27710. Copyright (C) 1994 Society for Neuroscience $0270-6474 / 94 / 145077-12 \$ 05.00 / 0$ of neurons (Rush et al., 1992) and that the addition of $\beta$-amyloid peptides to cultured hippocampal neurons leads to neuronal degeneration within $3 \mathrm{~d}$ (Cotman et al., 1992). These data have led to the suggestion that $\beta$-amyloid exerts a toxic effect and that neurons located near plaques with $\beta$-amyloid cores are therefore at risk (Yankner et al., 1990; Yankner and Mesulam, 1991; Cotman et al., 1992). However, this idea is controversial since other studies using the same approaches have not revealed neuronal damage (Games et al., 1992; Podlisny et al., 1992; Stein-Behrens et al., 1992); furthermore, some studies have revealed that under certain conditions in tissue culture, $\beta$-amyloid promotes neurite outgrowth (Yankner et al., 1990; Koo et al., 1993).

As another approach to understanding how plaques interact with adjacent neurons, we studied the relationship of granule cells in the dentate gyrus to the neuritic plaques in the molecular layer. We chose this neuronal population for two reasons. First, it is relatively homogeneous, facilitating possible morphological comparisons between neurons. Second, plaques in the dentate gyrus have a strong tendency to line up in the molecular layer approximately two-thirds of the way from the top of the hippocampal fissure (Crain and Burger, 1989), producing a precise spatial relationship to the dendrites of the granule cells. We reasoned that, given this spatial relationship, we might observe granule cell dendrites participating in plaques. Furthermore, we might also observe different changes in the dendrites depending on their location with respect to the plaques (Einstein and Crain, 1992). Specifically, we asked the following questions. Do granule cell dendrites become dystrophic in the vicinity of the plaques? Do plaques displace or attract dendrites in their vicinity? Do plaques induce morphological changes such as sprouting or loss of dendritic integrity?

To obtain the answers to these questions, we filled granule cells intracellularly with Lucifer yellow to visualize the dendrites and we counterstained the tissue with thioflavin-S to visualize the plaques. By doing so we found no examples of dystrophic neurites arising from granule cells. While there were degenerative changes in the dendrites from the AD cases, they were present on dendrites within plaques, beneath plaques, and in plaque-free regions. Thus, granule cell dendrites do not appear to be integral components of plaques and the degenerative changes in granule cell dendrites do not appear to be related specifically to the presence of plaques. Taken together, these data suggest that plaques have no direct effect on granule cells.

\section{Materials and Methods}

We obtained blocks of hippocampal tissue within $3 \mathrm{hr}$ postmortem from five demented patients with autopsy-proven AD (Khachaturian, 1985; Mirra et al., 1991) with ages ranging from 63 to 85 years (average $=70$ 

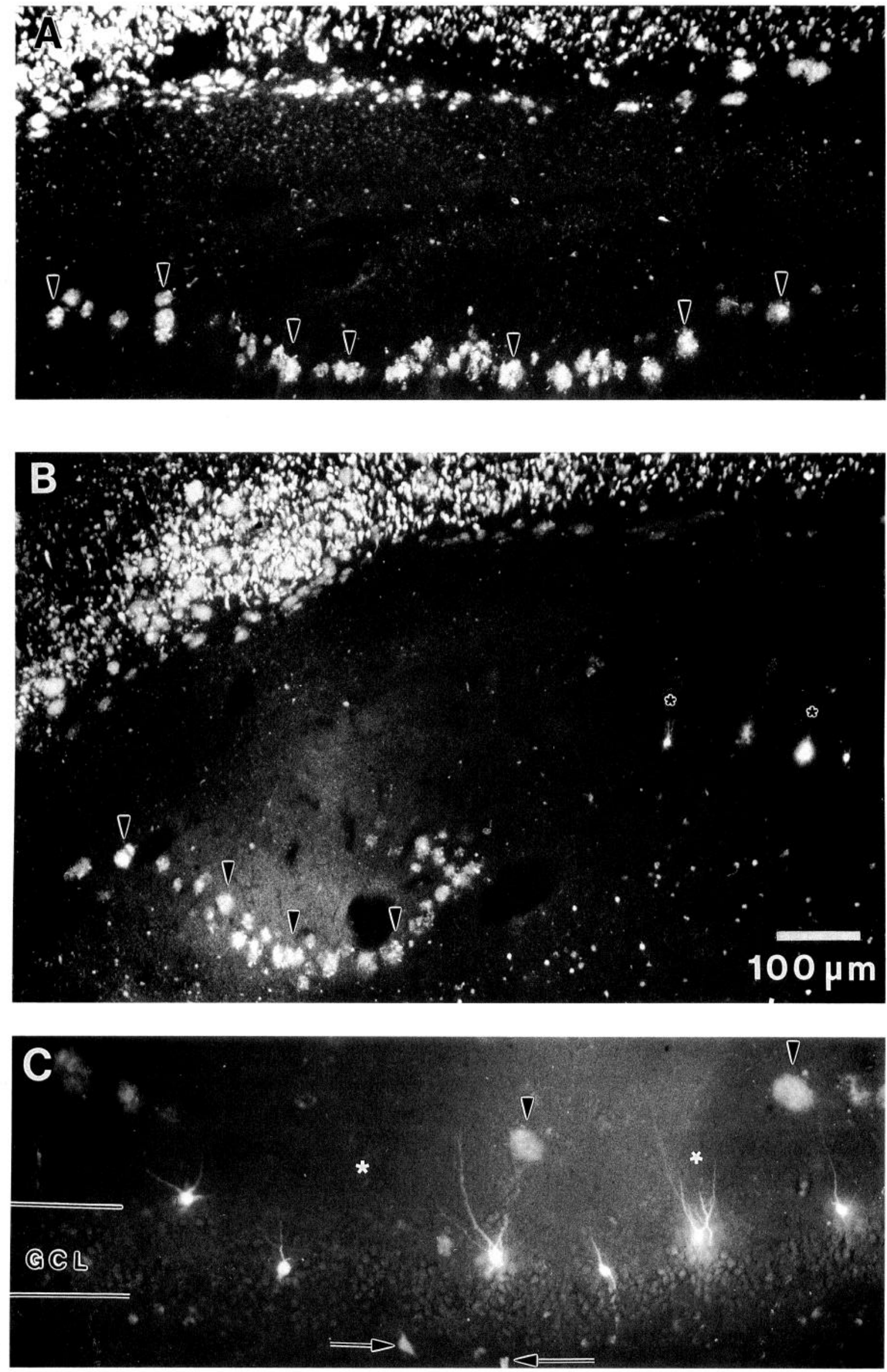


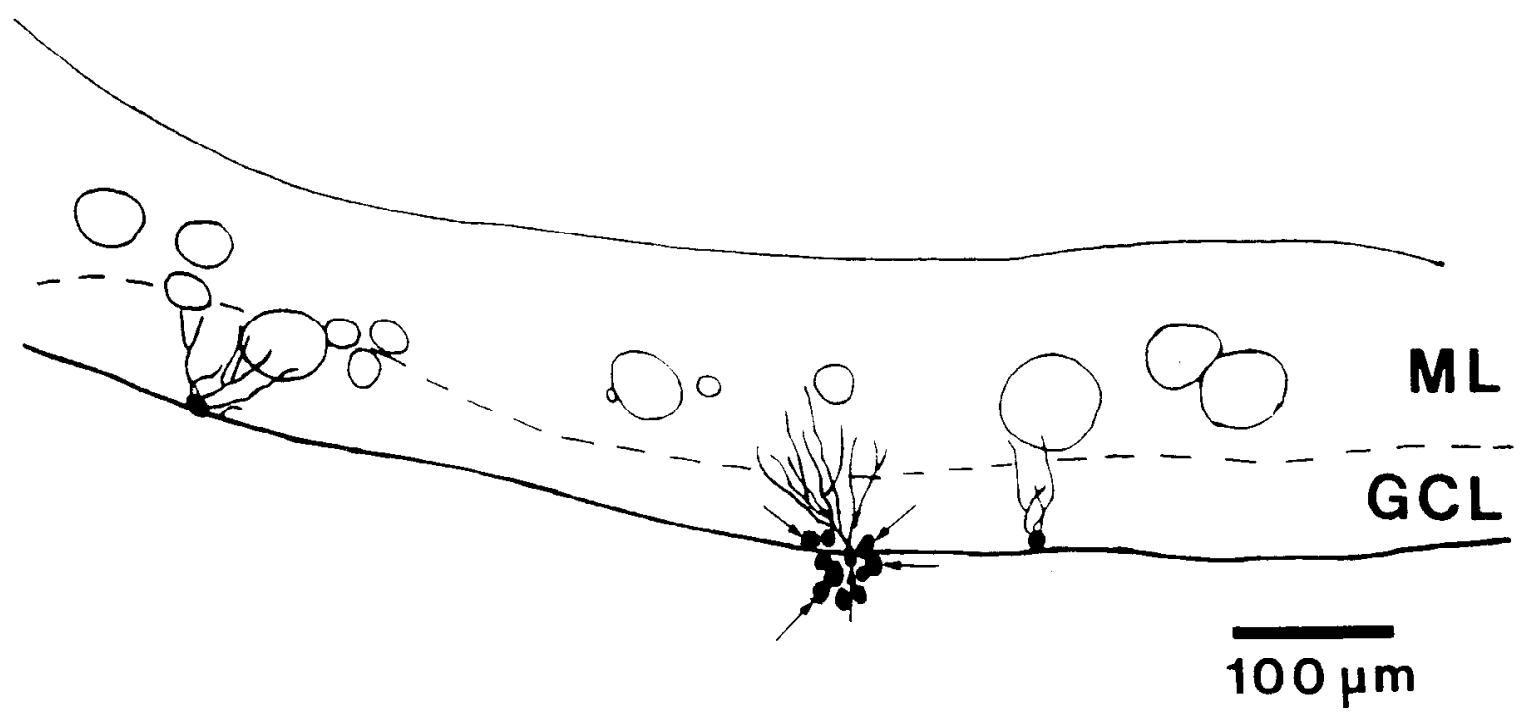

Figure 2. Camera lucida drawing of plaques and intracellularly filled granule cells in the dentate gyrus of a 63-year-old woman with AD. Plaques are outlined and appear as open circles. Cell bodies are filled. Arrows point to granule cell bodies that were intracellularly filled as a group but from which it was possible to trace dendrites from individual cells. $M L$, molecular layer; $G C L$, granule cell layer.

years) and from three age-matched controls with ages ranging from 66 to 74 years (average $=71$ years). The tissue was immediately placed in a mixture of cold $2.5 \%$ paraformaldehyde and $0.2 \%$ glutaraldehyde in $0.1 \mathrm{M}$ phosphate buffer. After immersion for $90 \mathrm{~min}$ to $2 \mathrm{hr}$, the tissue was removed from fixative, rinsed in cold phosphate buffer $(0.1 \mathrm{M}, \mathrm{pH}$ 7.4), sectioned at $300 \mu \mathrm{m}$ on a vibratome, and prepared for intracellular injection as previously described (Einstein, 1988; Einstein et al., 1993).

Intracellular injections with Lucifer yellow. Under epifluorescent illumination for Lucifer yellow (excitation wave length, 450-490; Nikon filter cube B-2A) the granule cell layer was evident as a smooth band of small cell bodies located between the hippocampal fissure and the autofluorescent lipofuscin granules of the hilar neurons (Fig. 1C). Since, at the time of injection, we did not know where the plaques would be located in a given tissue slice, we intracellularly filled as many granule cells in a single dentate gyrus as possible; in most cases, this meant at least four and usually more completely filled granule cells per slice. The location of intracellularly filled cells in each tissue slice was plotted at low magnification $(32 \times)$ using a camera lucida and a white pencil on black paper.

Each slice with filled cells was then rinsed in phosphate buffer $(0.1$ $\mathrm{M}, \mathrm{pH} 7.4$ ), postfixed in 4\% paraformaldehyde for at least $90 \mathrm{~min}$, and infiltrated in $25 \%$ sucrose in phosphate buffer $(0.1 \mathrm{M}, \mathrm{pH} 7.4)$.

Counterstaining for plaques and tangles. After determining the location of all the filled cells in a slice, we resectioned the slices at $60 \mu \mathrm{m}$ on a freezing microtome. These sections were collected serially and the sections belonging to one $300 \mu \mathrm{m}$ slice were mounted, together, on gelatin-coated slides where they were air dried for at least $48 \mathrm{hr}$ before being counterstained for plaques and tangles with thioflavin-S (Guntern et al.; 1992) and coverslipped with Aquamount. In this way we were able to visualize directly the relationships of granule cell dendrites to the senile plaques (Fig. $1 A-C$ ).

Confocal imaging. One section with many examples of filled granule cells in the region of the plaques was analyzed with a confocal microscope (Bio-Rad, MRC 600). Using a $488 \mathrm{~nm}$ excitation and a $515 \mathrm{~nm}$ barrier filter, serial images of a single granule cell with dendrites passing through a plaque were collected in $2 \mu \mathrm{m}$ increments through the entire plaque $(\sim 40 \mu \mathrm{m})$ for subsequent reconstruction and three-dimensional analysis. These individual images were transferred to a workstation (Sun) and were enhanced and reconstructed using Sunvision software.
Drawing granule cells. In both control and AD cases, we chose the best-filled granule cells to draw. We used an Olympus $100 \times$ objective and a camera lucida to trace the cells with a white pencil on black paper. When granule cells were located under plaques or their dendrites passed around, through, or between two neighboring plaques, the outline of the plaque was drawn with respect to the dendritic field. Although the cells were originally filled in $300 \mu \mathrm{m}$ slices, most filled cells had their cell bodies and dendritic tree in a single $60 \mu \mathrm{m}$ section. If a cell body was present in one section and the dendritic tree in another, the processes in both sections were drawn and then reconstructed for quantitative analysis.

Morphometric analysis. We analyzed the dendritic morphology using the methods of Hanks and Flood (1991). First we measured the total dendritic length of each drawn granule cell. We then subdivided the dendritic tree into segments (defined as the regions between branch points), measured the segments, and calculated an average segment length per neuron. Finally, we subclassified dendritic segments into "terminal," "next to terminal," and "other" (i.e., proximal) and calculated average values for these regions. We determined the number of spines per unit length of the dendrites by counting the total number of spines and dividing that number by the total dendritic length. Where dendrites passed through plaques, their spines and the length of the dendritic segments in the plaques were counted and measured separately.

Statistical analysis. For statistical analysis, granule cells were placed in one of three categories: control, AD-plaque, and AD-interplaque. The values for each morphological parameter of the neurons in each of the three groups were compared and the differences between groups were determined using two-tailed Student's $t$ tests.

\section{Results}

We intracellularly filled 100 granule cells in three age-matched controls and 178 cells in five cases with AD. On the average, we filled eight cells in each slice along a $2 \mathrm{~mm}$ length of the granule cell layer. After counterstaining the tissue with thioflavin-S, much of the autofluorescence was eliminated, yielding sections in which the Lucifer yellow-filled neurons stood out

Figure 1. Photomicrographs of $60 \mu \mathrm{m}$ coronal sections of the human hippocampus stained with thioflavin-S from two 71 -year-old women who died with AD. Arrowheads point to plaques. Black asterisks mark intracellularly filled neurons. White asterisks mark interplaque regions. $A$, Note numerous plaques and tangles in pyramidal cell layer (CAl) of the hippocampus (top) and how the plaques line up in the molecular layer (bottom). $B$, Plaques line up across only one-half of the dentate gyrus. Intracellularly filled neurons are in plaque-free regions. $C$, Intracellularly filled neurons lie beneath plaques as well as between plaques (interplaque regions). Arrows point to autofluorescent hilar neurons. $G C L$, granule cell layer. 


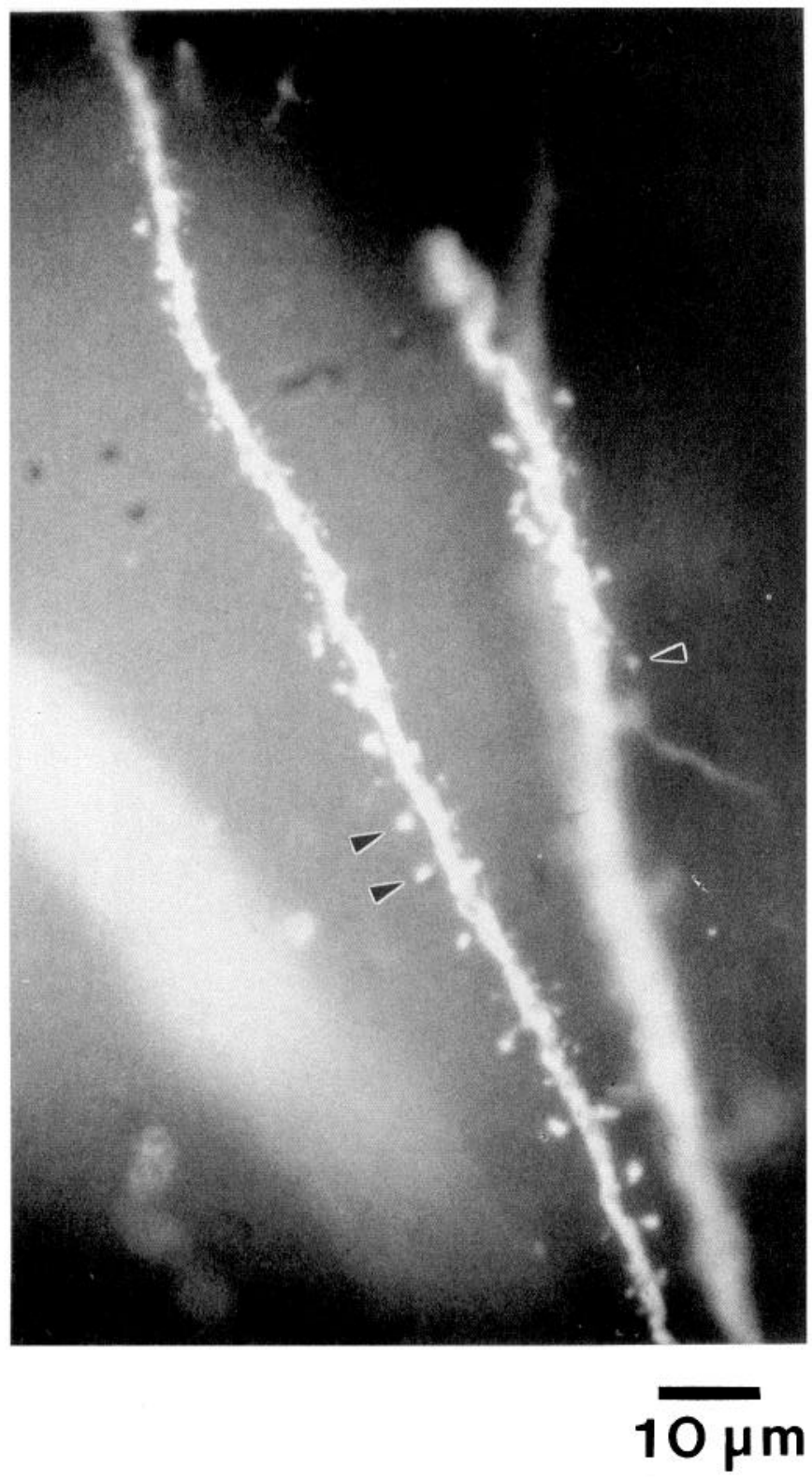

Figure 3. Photomicrograph of dendrites of a 74 year old man with cancer. Note how they are thick, straight, and profusely spiny. Arrowheads point to spines.

brightly against the background (Fig. $1 A-C$ ). In the control cases, without exception, there were no plaques in the molecular layer. In the $\mathrm{AD}$ cases, plaques in the pyramidal cell layers and the molecular layers were stained brightly (Fig. 1A). Often we found that the plaques did not extend across the molecular layer and that the Lucifer yellow-filled granule cells were in regions that contained no plaques (Fig. $1 B$ ); we called these plaque-free regions. However, more often, Lucifer yellow-filled granule cells were located between or underneath plaques (Fig. 1C). When they were located between plaques, we called these interplaque regions and when they were located beneath plaques, we called these plaque regions. Since no differences were found between neurons in the plaque-free and interplaque regions, these two categories were collapsed for subsequent analyses and are hereafter referred to, together, as interplaque regions.
Often, because granule cells have such small cell bodies, are so densely packed, and are joined by gap junctions, it was difficult to fill one cell body discretely. In these instances, even when dendrites were discretely filled, we often saw a blur of Lucifer yellow in the granule cell layer where the injection was made. However, upon drawing the cell body at high magnification it was possible to differentiate the individual cell bodies and to determine which dendrites belonged to them (Fig. 2). The quality of intracellular filling varied from neuron to neuron and from case to case (see Einstein et al., 1993, for discussion). We chose to analyze only the best neurons in each case, that is, those that had some dendrites that appeared filled to their terminal tips and had spines that were brightly fluorescent. This may have biased our results toward the granule cells that were the least damaged by AD. However, this approach did not eliminate the possibility of finding pathological changes in the AD cases because when granule cells were drawn, it was evident that, in comparison to the control examples, the dendritic trees of granule cells in the AD cases were severely attenuated and their spine number decreased.

Morphology of dendrites in controls. We analyzed four neurons from the control cases. As shown by others, the granule cell dendrites from this group were full and covered with spines (Figs. 3, 4, 5B,C) (de Ruiter and Uylings, 1987; Flood et al., 1987). They had relatively long dendrites with many dendritic segments and fairly long average segment lengths (Fig. 5A,D,E). Their terminal dendritic segments made up the largest proportion of their dendritic tree and their next-to-terminal dendrites made up the next largest proportion (Fig. $5 F-H$ ).

Morphology of dendrites in interplaque regions. We analyzed 11 granule cells located in interplaque regions. In these regions, granule cell dendrites appeared spindly with shrunken diameters, abnormal varicosities, and decreased numbers of spines (Figs. 6, 7). The $35 \%$ difference between the average number of spines per millimeter of dendrites in the control and AD interplaque groups was statistically significant (Fig. $5 C$ ). Compared to the dendrites in the control group, dendrites in the AD interplaque regions were about $50 \%$ shorter overall $(p<0.001)$, with $33 \%$ fewer dendritic segments and $19 \%$ shorter average segment lengths (Fig. 5D,E). As for the control cells, the terminal dendritic segments still made up the largest proportion of the dendritic tree. However, the dendritic trees of neurons located in interplaque regions were sparse and attenuated with shorter dendritic segments throughout their branches (Fig. $5 F-H$ ). We saw no evidence of sprouting such as increased numbers of dendritic twigs or abnormal excrescences within or adjacent to plaques.

Morphology of dendrites in plaque regions. At low magnification, using a conventional microscope, it appeared that the dendrites of granule cells lying beneath plaques often ended at the point at which the plaques began. However, granule cell dendrites did occasionally travel into the molecular layer beyond the plaques; in these cases, they often looked as though they had been pushed to one side of the plaque. There were also examples in which dendrites appeared to pass directly through the plaques (Fig. 9A). Since it was difficult in the conventional light microscope to achieve a thin enough focal plane to discern the actual spatial relationship between the granule cell dendrites and the plaques, we optically sectioned a $60 \mu \mathrm{m}$ slice of tissue into a series of two micron thick sections using a Bio-Rad MRC 600 confocal microscope. In this example, the dendrites did branch directly into the plaque (Fig. 8). Therefore, we assumed 


\section{CONTROL}
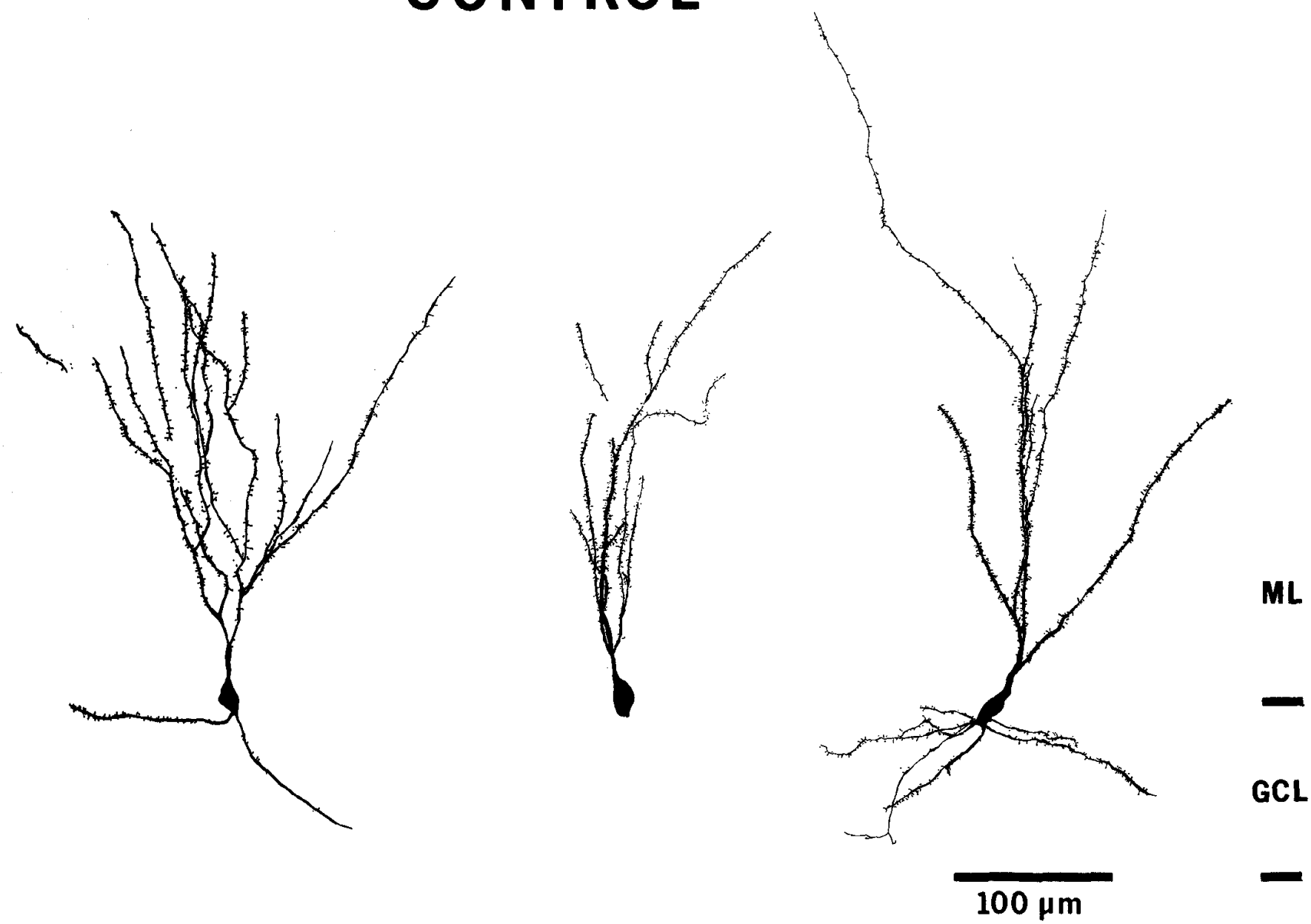

Figure 4. Camera lucida drawings of three granule cells taken from age-matched controls. Since the drawings are of resectioned material, not all of the dendrites are continuous in the plane of section represented here.

that if a dendrite looked like it passed through a plaque, it probably did.

We analyzed nine neurons that had dendrites that were located directly beneath or within plaques (plaque regions). Whether the dendrites stopped short, pushed around, or passed through the plaques, they looked very much like the ones in interplaque regions (Figs. 9, 10). As in the interplaque regions, dendrites in plaque regions appeared spindly, with shrunken diameters, abnormal varicosities, and decreased numbers of dendritic spines. When dendrites passed through the plaques, they maintained their structural integrity; they were not bloated and stringy as were the dystrophic neurites that stained with thioflavin-S. They were also distinct from the dystrophic neurites in that their shape in the plaque was continuous with their shape before they entered the plaque, and they continued to bear spines within the plaque (Fig. $9 A-C$ ). As in the dendrites located in the interplaque regions, we saw no evidence of sprouting.

There was a $44 \%$ difference in the number of spines/ $\mu \mathrm{m}$ between plaque regions and control cases $(p<0.01)$. Compared to the dendrites in the control group, dendrites in the plaque regions had $57 \%$ shorter total dendritic lengths comprising both fewer dendritic segments and shorter average segment lengths
(Fig. 5A,D,E). Again, only the difference in total length was statistically significant $(p<0.01)$ (Fig. $5 A)$. The terminal dendritic segments still made up the largest proportion of their dendritic tree. However, all parts of the dendritic tree were severely shrunken (Fig. $5 F-H$ ).

Interestingly, none of the values for dendrites in plaque regions differed significantly from those in the interplaque regions (Fig. $5 A-H)$. Thus, the dendritic trees of granule cells in plaque regions appeared sparse and attenuated, their overall appearance closely resembling that of interplaque cells both qualitatively and quantitatively.

\section{Discussion}

By intracellularly filling human dentate granule cells with $\mathrm{Lu}$ cifer yellow in a lightly fixed slice preparation we were able to observe directly the relationship of the whole granule cell to neuritic plaques in the molecular layer of the human hippocampus. We found, in agreement with Golgi studies, that dentate granule cells suffer dendritic changes in AD; their dendrites decrease in length, shrink in diameter, develop abnormal varicosities, and lose spines (de Ruiter and Uylings, 1987; Flood et al., 1987). The two new findings are (1) granule cell dendrites do not form abnormal neurites within plaques and (2) other 


\section{DENDRITIC SPINES}
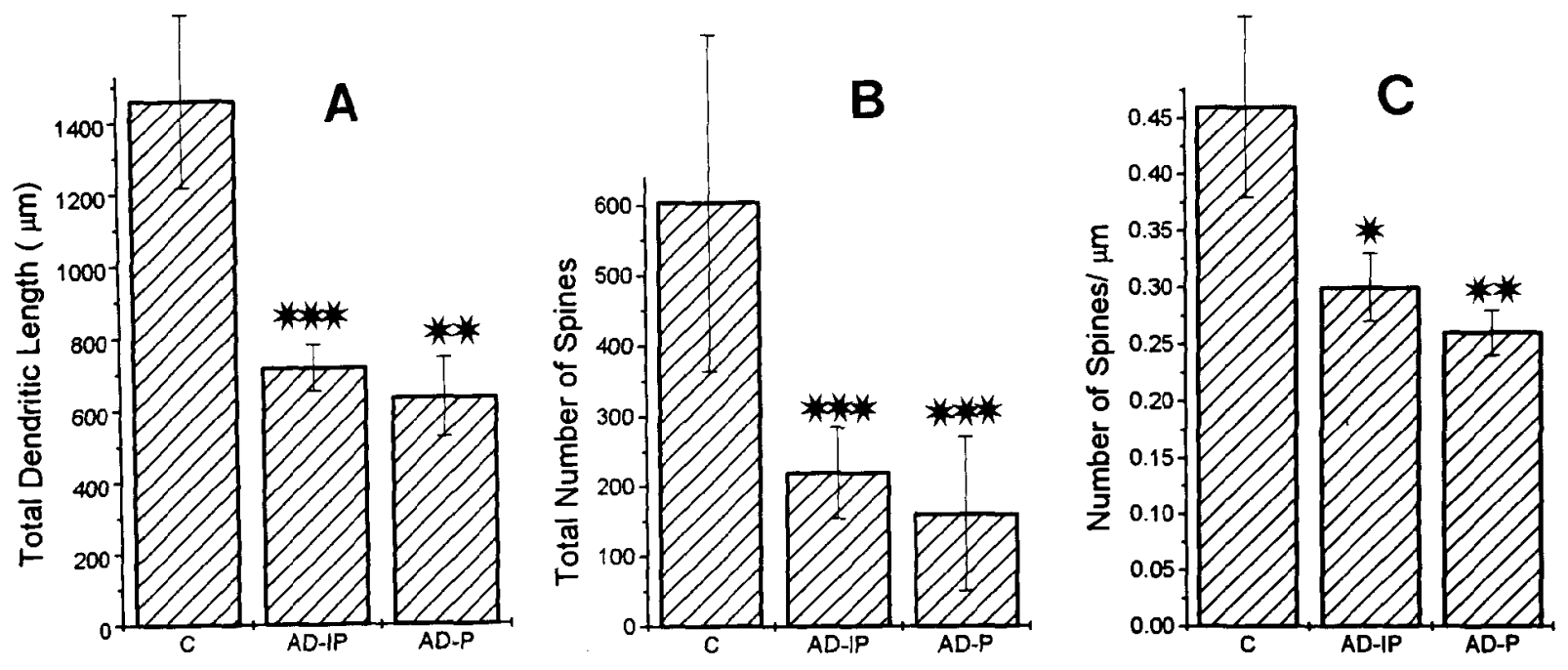

DENDRITIC SEGMENTS
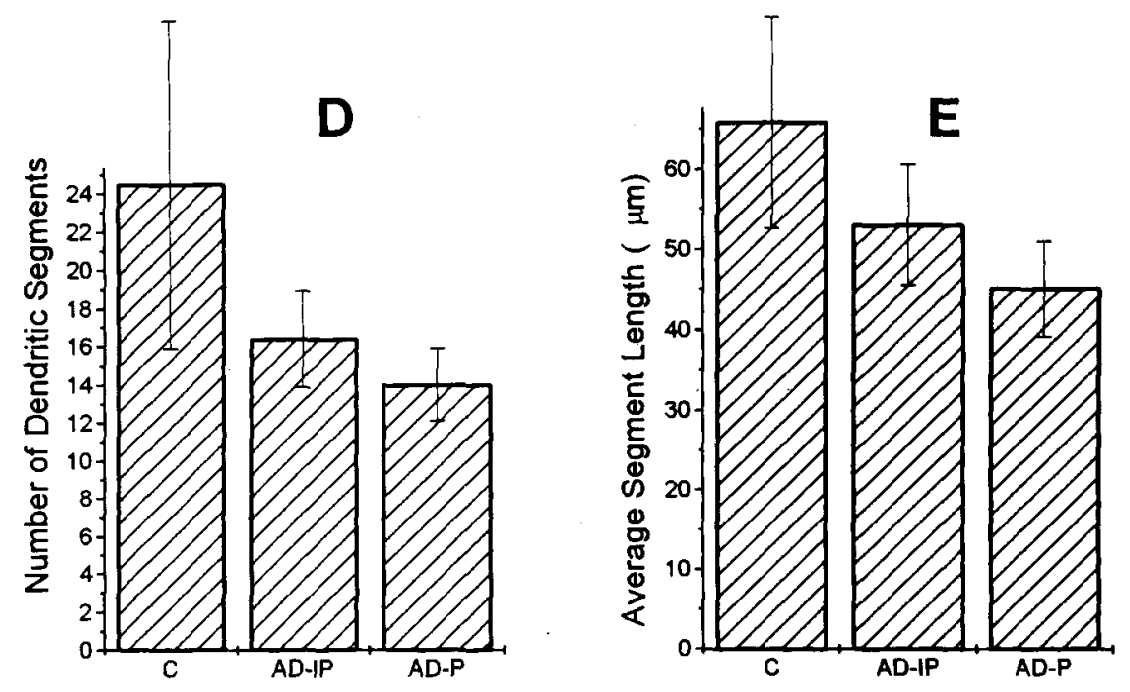

DENDRITIC LENGTHS
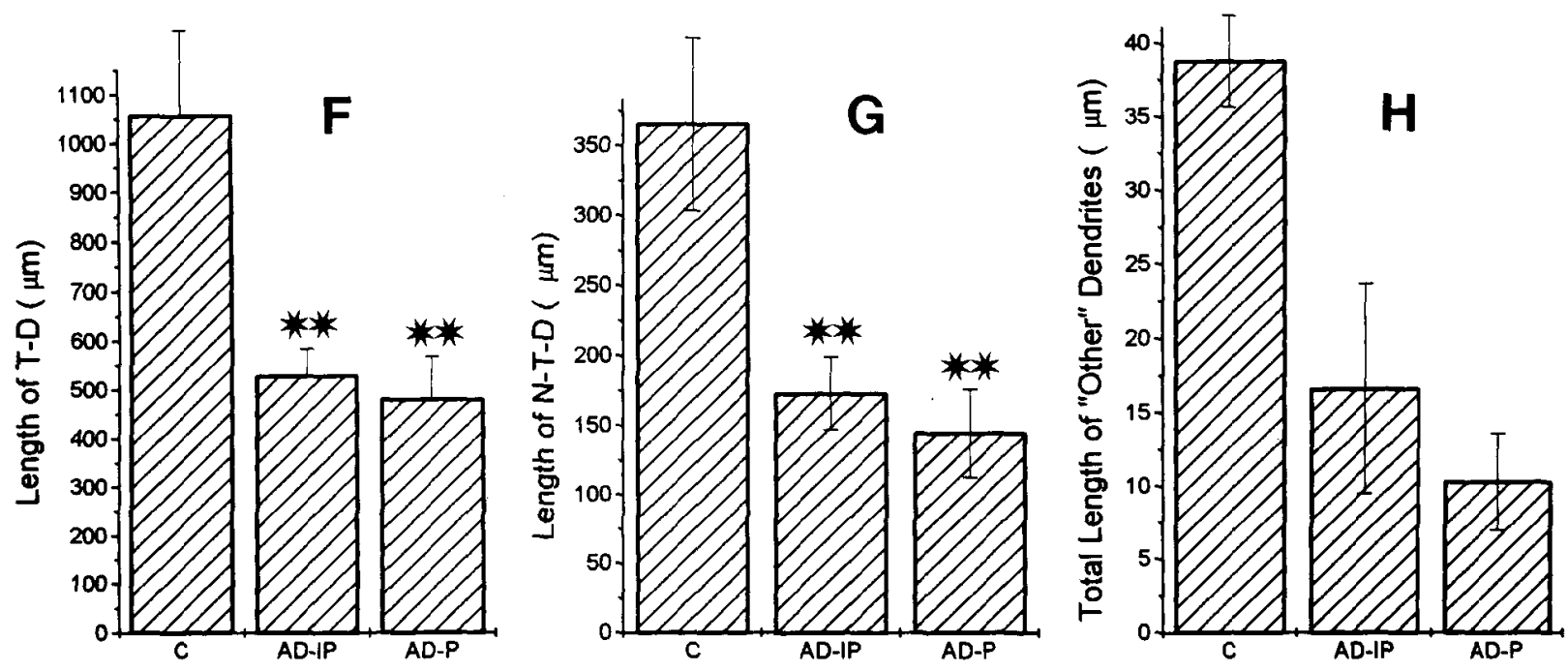

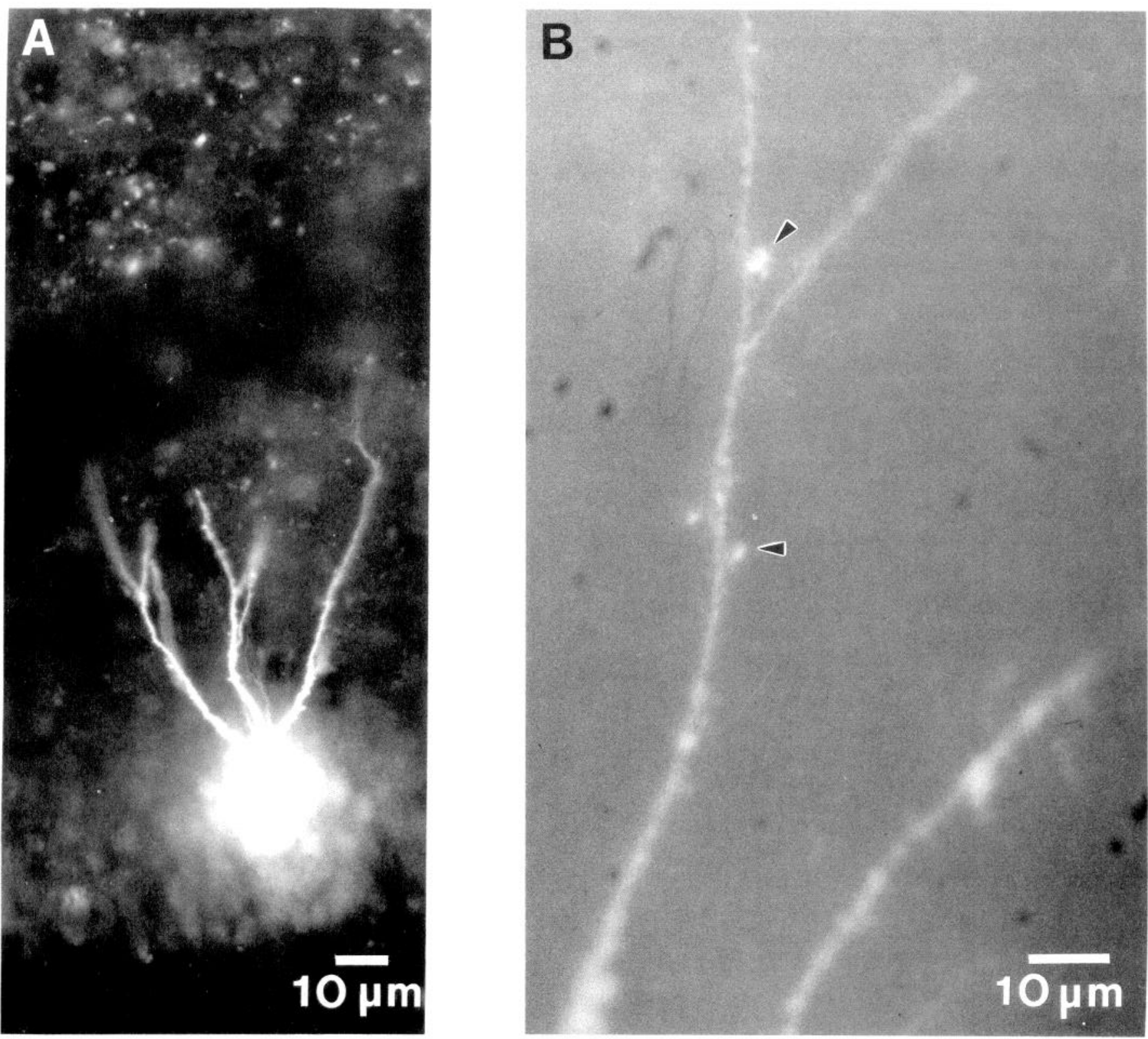

Figure 6. Photomicrographs of granule cells and their dendrites in interplaque regions in two 71 year old women who died with AD. A, High background fluorescence is due to spillage of Lucifer yellow during the injection. $B$, Note the thin diameter and paucity of spines. Arrowheads point to spines.

types of morphological changes to the dendrites occur whether or not the dendrites are located near plaques, pass through plaques, or are located in plaque-free regions. These findings suggest that the characteristic location of the plaques in the molecular layer is not determined by the location or branching pattern of granule cell dendrites and that plaques have no direct effect on granule cells.

The data displayed in Figure 5 indicate a slight tendency towards more severe dendritic changes in plaque regions. How- ever, these differences were much smaller than the differences between AD and control cells and were never statistically significant. It might be argued that pre- and/or postmortem conditions differentially affected the quality of intracellular filling in the three groups and therefore produced artifactual distortions independent of AD-related changes or failed to reveal subtle changes in very fine processes (Einstein et al., 1993). However, we do not think the lack of significant differences between dendrites located in interplaque and plaque regions can be attributed

Figure 5. Quantitative analysis of dendritic morphology of granule cells in control cases $(C ; N=4$ neurons), AD interplaque regions $(A D-I P ; N$ $=11$ neurons), and AD plaque regions ( $A D-P ; N=9$ neurons). Error bars indicate SEMs. Note that lack of significant differences in $H$ reflects small sample sizes. Asterisks indicate values statistically different from control (two-tailed Student's $t$ test): ${ }^{* * *}, p<0.001 ;{ }^{* *}, p<0.01 ;{ }^{*}, p<$ 0.05. $N$ - $T$ - $D$, next-to-terminal dendrite; $T-D$, terminal dendrite. 


\section{N T ERPLAQUE}
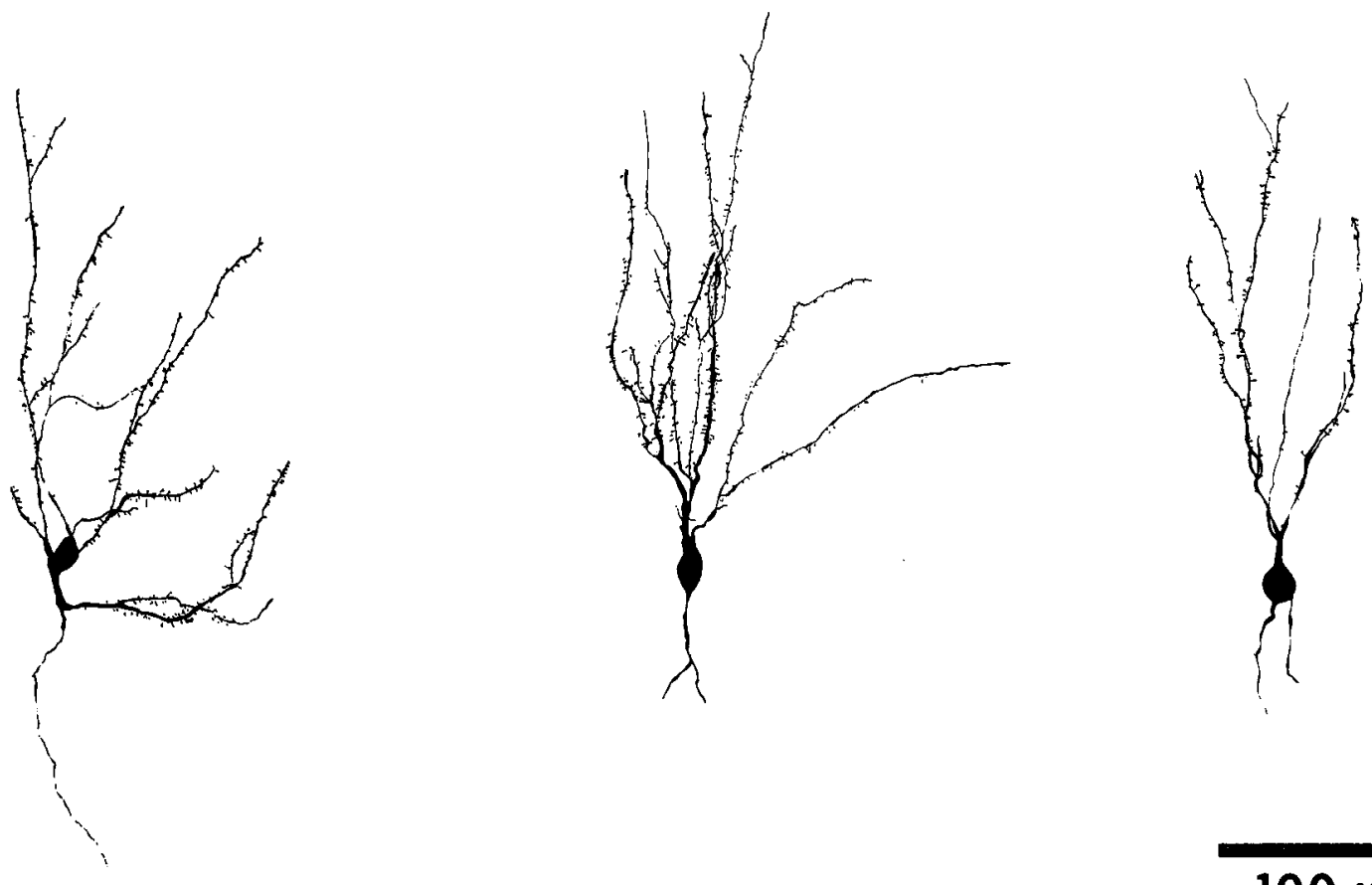

\section{$100 \mu \mathrm{m}$}

Figure 7. Camera lucida drawings of three granule cells taken from interplaque regions in patients with AD.

to poor filling since the cells examined lacked the typical features of poorly filled neurons (Einstein et al., 1993). Furthermore, our data show the same statistically significant differences between granule cell dendrites in control and AD cases that previous studies using other methods have demonstrated (Flood and Coleman, 1986).

Our observation that granule cell dendrites entering plaques did not resemble dystrophic neurites in any way is noteworthy since other types of neurons do have dendrites that can be identified as dystrophic and that do participate in plaques (Probst et al., 1989). However, in these cases the dystrophic neurites arose from tangle bearing neurons. The fact that granule cells rarely, if ever, contain neurofibrillary tangles may therefore explain why their dendrites did not contribute to plaques. This would suggest that proximity to plaques is not by itself sufficient to induce the formation of dystrophic neurites by all neighboring neurons.

Another key observation was the absence of morphologically abnormal sprouting in any portion of the granule cell dendritic tree, including portions that passed directly through plaques. While Golgi studies of pyramidal neurons have shown both dendritic (Scheibel and Tomiyasu, 1978; Probst et al., 1983;

Figure 8. Photomicrographs of optical sections of granule cell dendrites as they pass through plaques. The frames represented are separated by 6 $\mu \mathrm{m}$ each. Two plaques are present and the dendrites pass through both of them $(D, H)$. Note in $I$ how the plaque on the left ends before the dendrites do. Long arrows $(C, F, I)$ point to dystrophic neurites in the plaques. Note that these are shorter and coarser than the dendrites originating from granule cell bodies. Short arrows $(B)$ point to the edges of the two plaques. Arrowheads $(E-H)$ point to spines on dendrites within the plaques. 

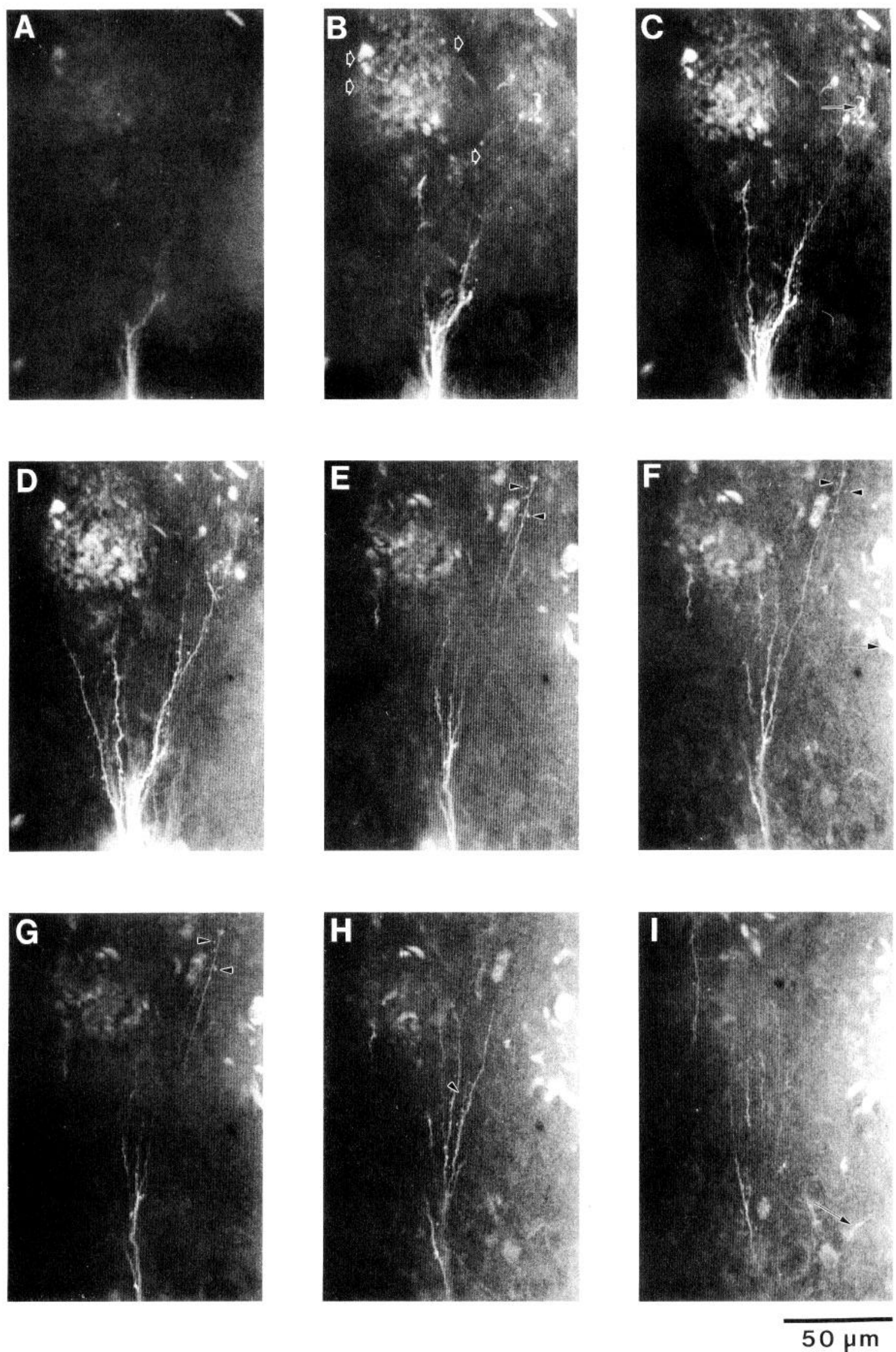

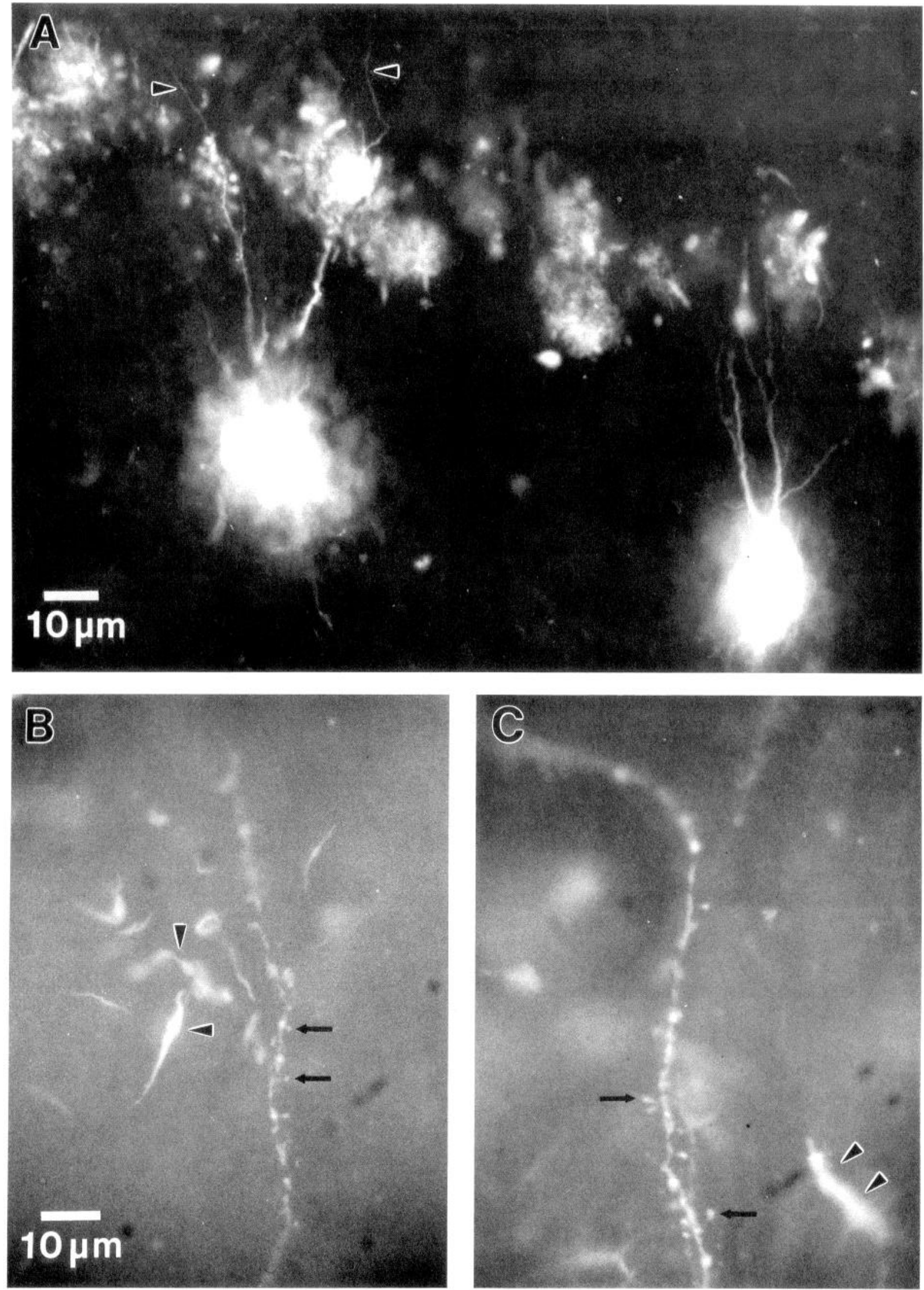

Figure 9. Photomicrograph of two intracellularly filled neurons and their dendrites as they pass through plaques. Tissue taken from a 71 -yearold woman with AD. A, Arrowheads point to dendrites as they emerge from the plaque in the molecular layer. $B$ and $C$, Note how, although shrunken and suffering a loss of spines, the dendrites have intact boundaries, are not stained with thioflavin-S, continue to bear spines, and have a very different qualitative appearance from the stained dystrophic neurites. Arrowheads point to neurites. Arrows point to spines. 


\section{PLAQUE}
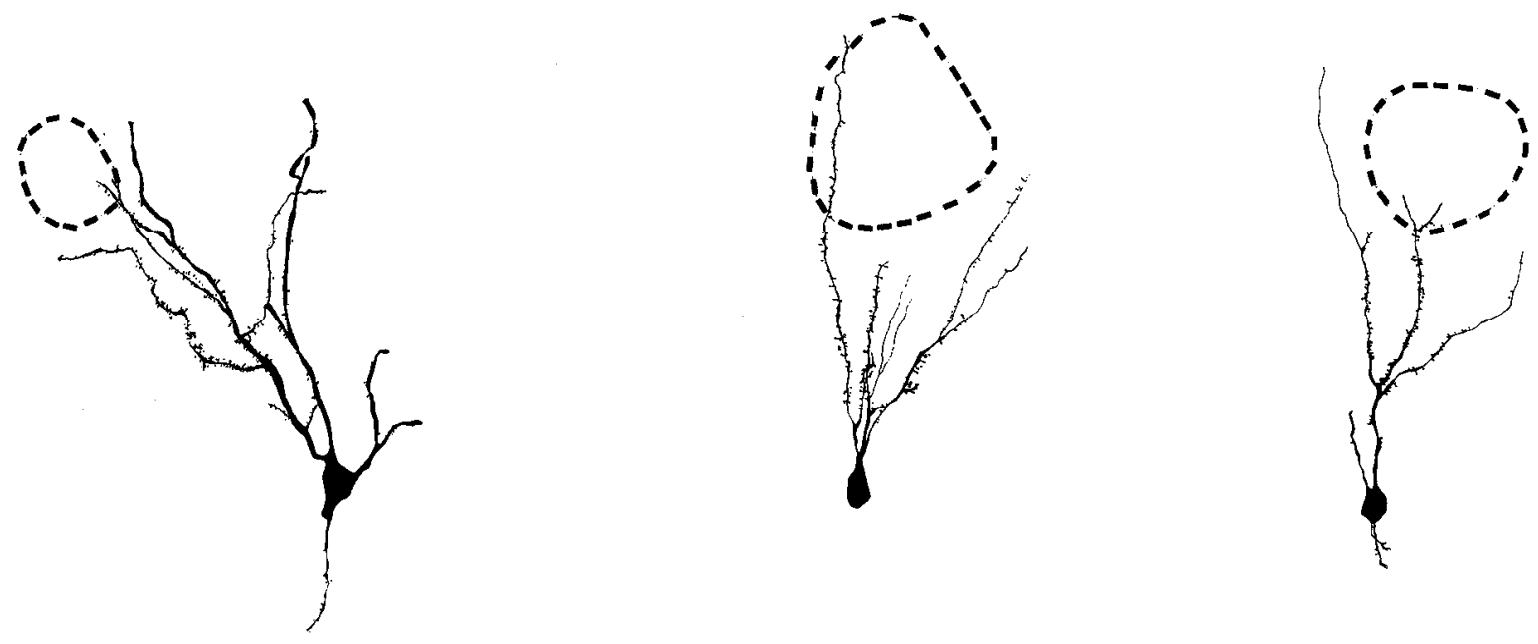

\section{$100 \mu \mathrm{m}$}

Figure 10. Camera lucida drawing of three examples of granule cells taken from plaque regions in paticnts with AD. Broken circles indicate plaques.

Ihara, 1988; Masliah et al., 1991) and axonal (Masliah et al., 1991) sprouting within or in the vicinity of plaques, our data indicate that, just as proximity to plaques does not necessarily induce dystrophic neurite formation, proximity to plaques does not necessarily induce abnormal sprouting. While we cannot rule out the possibility of normal dendritic sprouting throughout the molecular layer as a result of cholinergic reinnervation, it cannot be determined by our experimental paradigm. However, in contrast to the normal dendritic sprouting observed in experimental animals after entorhinal cortical lesions (Mathews et al., 1976; Caceres and Steward, 1983), it has been noted that there is an apparent lack of normal dendritic sprouting in AD (Flood and Coleman, 1986).

If the plaques are not directly affecting granule cell dendrites, what then is responsible for the atrophy and spine loss on granule cells in AD? We think a likely candidate for this destruction is simple denervation. The types of dendritic changes that we see are consistent with the morphological changes observed after deafferentation (Kemp and Powell, 1971) and, specifically, deafferentation due to perforant pathway ablation (Parnavelas et al., 1974; Caceres and Steward, 1983; Nitsch and Frotscher, 1991). The well-documented loss of the pyramidal neurons in entorhinal cortex in AD, as well as the loss of lesser afferent sources such as the septal neurons, deprives the granule cells of their major inputs (Hyman et al., 1984; Gertz et al., 1987; Lippa et al., 1992). Indeed the net loss of synapses in the outer molecular laycr is dircctly proportional to the loss of entorhinal cortical neurons (Lippa et al., 1992). Thus, the loss of inputs and their trophic or activity-dependent influences might well be more responsible for the shrinkage of the dendritic tree and loss of dendritic spines than any local toxic effects of plaque constituents.

The absence of specific plaque-related changes in the granule cell's dendritic tree does raise the fundamental issue of why plaques have been associated with changes in neurons and their dendrites elsewhere in cortex. One possibility is that some neuronal populations might be more susceptible to plaque-induced damage (Mountjoy et al., 1983; Pearson et al., 1985). Alternatively, plaques or their components (e.g., $\beta$-amyloid) might only be detrimental or trophic under certain as yet to be defined conditions (Yankner, 1990). Finally, it is possible that the coincidence of plaques with neuronal changes is just that-coincidence, with multiple pathogenetically indepcndent processes overlapping in space and time. This would imply that plaque formation is only one of multiple toxic/degenerative processes in AD. 


\section{References}

Alzheimer A (1986) A characteristic disease of the cerebral cortex. In: The early story of Alzheimer's disease (Bick K, Amaducci L, Pepeu $G$, eds and trans). Padua: Liviana.

Caceres A, Steward O (1983) Dendritic reorganization in the denervated dentate gyrus of the rat following entorhinal cortical lesions: a Golgi and electron microscopic analysis. J Comp Neurol 214:387403.

Cotman CW, Pike CJ, Copani A (1992) B-Amyloid neurotoxicity: a discussion of in vitro findings. Neurobiol Aging 13:587-590.

Crain BJ, Burger PC (1988) The laminar distribution of neuritic plaques in the dentate gyrus of patients with Alzheimer's disease. Acta Neuropathol (Berl) 76:87-93.

de Ruiter JP, Uylings HBM (1987) Morphometric and dendritic analysis of dentate gyrus granule cells in human aging and senile dementia. Brain Res 402:217-229.

Einstein G (1988) Intracellular injection of Lucifer Yellow into cortical neurons in lightly fixed sections and its application to human autopsy material. J Neurosci Methods 26:95-103.

Einstein G, Crain BJ (1992) Intracellular injections reveal the relationship of granule cell dendrites to neuritic plaques in Alzheimer's disease. Soc Neurosci Abstr 18:198.

Einstein G, Farris D, Crain BJ (1993) Investigating single neurons in human autopsy material. In: Morphological investigations of single neurons in vitro (Meredith G, Arbuthnott G, eds), pp 105-127. Sussex: Wiley.

Flood DG, Coleman P (1986) Failed compensatory dendritic growth as a pathophysiological process in Alzheimer's disease. Can J Neurol Sci 13:475-479.

Flood DG, Buell SJ, Horwitz GJ, Coleman PD (1987) Dendritic extent in human dentate gyrus granule cells in normal aging and senile dementia. Brain Res 402:205-216.

Games D, Khan KM, Soriano FG, Keim PS, Davis DL, Bryant K, Lieberburg I (1992) Lack of Alzheimer pathology after $\beta$-amyloid injections in rat brain. Neurobiol Aging 13:569-576.

Gertz HJ, Cervos-Navarro, Ewald V (1987) The septo-hippocampal pathway in patients suffering from senile dementia of Alzheimer's type. Evidence for neuronal plasticity? Neurosci Lett 76:228-232.

Guntern R, Bouras C, Hof PR, Vallet PG (1992) An improved thioflavin-S method for staining neurofibrillary tangles and senile plaques in Alzheimer's disease. Experientia 48:8-10.

Hanks SD, Flood DG (1991) Region-specific stability of dendritic extent in normal human aging and regression in Alzheimer's disease. I. CA1 of hippocampus. Brain Res 540:63-82.

Hyman BT, Van Hoesen GW, Damasio AR, Barnes CL (1984) Alzheimer's disease: cell-specific pathology isolates the hippocampal formation. Science 225:1168-1170.

Hyman BT, Kromer LJ, Van Hoesen GW (1987) Reinnervation of the hippocampal perforant pathway zone in Alzheimer's disease. Ann Neurol 21:259-267.

Ihara Y (1988) Massive somatodendritic sprouting of cortical neurons in Alzheimer's disease. Brain Res 459:138-144.

Kemp J, Powell TPS (1971) The termination of fibres from the cerebral cortex and thalamus upon dendritic spines in the caudate nucleus: a study with the Golgi method. Philos Trans R Soc Lond [Biol] 262: $429-439$.

Khachaturian ZS (1985) Diagnosis of Alzheimer's disease. Arch Neurol 42:1097-1105.

Koo EH, Park L, Selkoe DJ (1993) Amyloid $\beta$-protein as a substrate interacts with extracellular matrix to promote neurite outgrowth. Proc Natl Acad Sci USA 90:4748-4752.

Lippa CF, Hamos JE, Pulaski-Salo D, Degennaro LJ, Drachman DA (1992) Alzheimer's disease and aging: effects on perforant pathway perikarya and synapses. Neurobiol Aging 13:405-411

Masliah E, Mallory M, Hansen L, Alford M, Albright T, DeTeresa R, Terry R, Baudier J, Saitoh T (1991) Patterns of aberrant sprouting in Alzheimer's disease. Neuron 6:729-739.

Mathews DA, Cotman C, Lynch G (1976) Electron microscopic study of lesion induced synaptogenesis in the dentate gyrus of the adult rat. II. Reappearance of morphologically normal synaptic contacts. Brain Res 115:23-41.

Mirra SS, Heyman A, McKeel D, Sumi SM, Crain BJ, Brownlee L, Vogel FS, Hughes JP, van Belle G, Berg L (1991) The consortium to establish a registry for Alzheimer's Disease (CERAD). II. Standardization of the neuropathological assessment of Alzheimer's disease. Neurology 41:479-486.

Mountioy CQ, Roth M, Evans NJR, Evans HM (1983) Cortical neuronal counts in normal elderly controls and demented patients. Neurobiol Aging 4:1-11.

Nitsch R, Frotscher M (1991) Maintenance of peripheral dendrites of GABAergic neurons requires specific input. Brain Res 554:304-307.

Parnavelas JG, Lynch G, Brecha N, Cotman CW, Globus A (1974) Spine loss and regrowth in hippocampus following deafferentation. Science 248:71-73.

Pearson RCA, Esiri MM, Hiorns RW, Wilcock GK, Powell TPS (1985) Anatomical correlates of the distribution of the pathological changes in the neocortex in Alzheimer disease. Proc Natl Acad Sci USA 82: $4531-4534$.

Podlisny MB, Stephenson DT, Forsch MP, Lieberburg I, Clemens JA, Selkoe DJ (1992) Synthetic amyloid $\beta$-protein fails to produce specific neurotoxicity in monkey cerebral cortex. Neurobiol Aging 13: 561-568.

Probst A, Basler V, Bron B, Ulrich J (1983) Neuritic plaques in senile dementia of Alzheimer type: a Golgi analysis in the hippocampal region. Brain Res 268:249-254.

Probst A, Anderton BH, Brion JP, Ulrich J (1989) Senile plaque neurites fail to demonstrate anti-paired helical filament and antimicrotubule-associated protein-tau immunoreactive proteins in the absence of neurofibrillary tangles in the neocortex. Acta Neuropathol (Berl) 77:430-436.

Rush DK, Aschmies S, Merriman MC (1992) Intracerebral $\beta$-amyloid (25-35) produces tissue damage. Is it neurotoxic? Neurobiol Aging $13.591-594$.

Scheibel AB, Tomiyasu U (1978) Dendritic sprouting in Alzheimer's presenile dementia. Exp Neurol 60:1-8.

Stein-Behrens BK, Adams M, Yeh M, Sapolsky R (1992) Failure of beta-amyloid protein fragment $25-35$ to cause hippocampal damage in the rat. Neurobiol Aging 13:577-580.

Wilcock GK, Esiri MM (1982) Plaques, tangles, and dementia: a quantitative study. J Neurol Sci 56:343-356.

Yankner B (1992) Commentary and perspective on beta amyloid toxicity. Neurobiol Aging 13:615-616.

Yankner BA, Mesulam M-M (1991) B-Amyloid and the pathogenesis of Alzheimler's disease. Semin Med Beth Israel I Iosp 325:1 849-1 857.

Yankner BA, Duffy LK, Kirschner DA (1990) Neurotrophic and neurotoxic effects of amyloid $\beta$ protein: reversal by tachykinin neuropeptides. Science 250:279-282. 